\title{
A THEORETICAL STUDY OF THE NO-CLAIM BONUS PROBLEM
}

\author{
MARCEL DeRron, \\ Zurich, Switzerland \\ I. INTRODUCTION
}

The no-claim bonus problem has given rise to a considerable amount of discussion throughout the whole world. There is quite a difference of opinion among the actuaries and other experts concerned in this field and several exchanges of view have taken place the last few years. The ASTIN section of the Permanent Committee has been well aware of this fact and it has devoted one Colloquium to this subject and discussed it at others.

In I959 the major part of the La Baule meeting was dedicated to this subject and attention was focussed on this problem once again at Rättvik in I96r. Nevertheless controversies on this subject still continue. Almost every conference where the bonus problem is discussed is marked by a widespread difference of opinion.

As is well known, the claim frequencies under insurance policies show a considerable heterogeneity, especially in the early years. It is not possible to get homogeneous sub-groups by means of a continuous subdivision; what may be gained in homogeneity, is lost in credibility. It seems therefore that a subsequent adjustment of premiums according to the past claim record may well be a suitable way of obtaining a fair premium.

Those who are in favour of a rating procedure granting a bonus at a careful driver will stress that criticism is useless as long as no better solution is available, whereas actuaries who reject such a rating system argue that the unfairness of a flat rate is not at all eliminated by means of a bonus.

It is obvious that this latter point of view is mainly adopted in countries where only few features of the car and the driver are included in the tariff, i.e. in Germany and Switzerland. As may be seen from the paper by Mehring [5]*) printed in this issue of the

*) ij see list of references. 
Bulletin, some progress had been made as to the rating procedure to be applied in Germany. Nevertheless only very few characteristics form the basis of the automobile liability insurance in Germany.

In Switzerland only the features "kind of vehicle" and "horsepower" are taken into account in determining rates and it is assumed that the neglected characteristics of the underlying risk are eliminated by means of a bonus. The latest rate revision of automobile liability insurance in Switzerland has brought the introduction of a new bonus/malus-system according to which the careful driver receives a credit of $40 \%$ at the most, whereas the accident-prone driver may be discredited to a maximum of $280 \%$ of the initial premium. For the purpose of this paper, we are only concerned with the pure bonus system.

\section{THE UNFAIRNESS OF A TARIFF}

In Germany and Switzerland the question of the unfairness of the motor car rates has been discussed in many ways. It is selfevident that the smaller the number of classification groups, the more heterogeneous the statistical data will be. While most competent actuaries in these countries (Ammeter, Sachs, Mehring) agree with the no-claim bonus-system, there are some economists who doubt whether such a rating procedure is really well-founded. In particular Prof. Gürtler has expressed a controversial opinion in several papers $[2,3,4]$. Prof. Gürtler, who always presents his thoughts in a very clear manner, has based his investigations on some very simple assumptions and has introduced a very plausible standard for evaluating the fairness of the tariff. This measure is called by him "the error ratio" and represents the quotient between the absolute amount of all differences between the office premium after deducting an eventual bonus and the "true" premium and the total of all premiums paid after deduction of the bonus.

For clarity the following notation will be used:

$$
\begin{aligned}
\text { charged premium } & =\text { office premium }- \text { bonus granted } \\
\text { true premium } & =\text { premium corresponding to the individual } \\
& \text { claim rate }
\end{aligned}
$$

The error ratio $E R$ can thus be defined as follows: 


$$
E R=\frac{\Sigma \mid \text { charged pr. }- \text { true pr. } \mid}{\Sigma \text { charged premiums }}
$$

Assuming that a portfolio consists of 9000 careful drivers with an annual claim rate of $0, I$ and 1000 accident-prone drivers with a claim rate of $\mathrm{I}, \mathrm{O}$ and assuming further that the average and constant cost of a claim is $\mathrm{I} 200$, the total claim costs amount to 2280 ooo and the flat rate premium is therefore 228 . Hence the following $E R$ is obtained:

$\begin{array}{lccc}\text { driver } & \begin{array}{c}\text { charged } \\ \text { premium }\end{array} & \begin{array}{c}\text { true } \\ \text { premium }\end{array} & |(\mathrm{I})-(2)| \\ \text { careful } & (\mathrm{I}) & (2) & \\ \text { acc.-prone } & 228 & \mathrm{I} 20 & \mathrm{I} 08 \\ & 228 & \mathrm{I} 200 & 972 \\ \quad E R=\frac{9000 \times \mathrm{I} 08+\mathrm{I} 000 \times 972}{\mathrm{I0} 000 \times 228}=0,853\end{array}$

The $E R$ lies between o and $x$. If $E R=0$, the ideal rating system is found, if $E R=\mathrm{I}$, the levied premiums disregard completely the underlying risk. An $E R$ of 0,853 is certainly a most unsatisfactory rating procedure. An optimal solution can therefore be described by a rating procedure which minimizes the $E R$.

These assumptions raise again the problem of accident-proneness and it is doubtful whether investigations which are based on such rough assumptions can lead to significant results. The criticism was expressed mainly by Sachs [6]. All relevant statistical data show a considerable heterogeneity and the claim distribution emerging can be expressed by a compound Poisson process. It is not at all certain whether this is due to differences in accident probabilities of the underlying risk; it might well be due to different exposures of similar risks.

The author is convinced that the proneness concept is at least suspect. The purpose of the present paper is to show that the results found by Gürtler may be extended and complemented, even when his own tools are used for analysis. For convenience the notations of careful and accident-prone drivers are used in the following, but the use of these terms is not to be regarded as implying the existence of a proneness factor in motor insurance. 


\section{GÜRTLER'S MODEL}

Gürtler divides a portfolio into different subgroups with specific but constant claim rates. Each subgroup is homogeneous and its stochastic process described by a Poisson distribution. The investigations are based on a considerable amount of computation, by varying the number of policy-holders in each subgroup and the claim rates in every possible way. For the example mentioned before, the largest optimal $E R$ was found. Further considerations are based on these simple assumptions.

As has been mentioned previously, competent German actuaries like Sachs and Mehring have rejected these oversimplified assumptions which imply an accident-proneness. However, Gürtler has found a disciple for his theories; in a paper Tröblinger [ 7 ] is analyzing the following statistical observations from a German insurance company:

$\begin{array}{cr}\begin{array}{c}\text { Number of claims } \\ \text { per policy }\end{array} & \text { Number of po } \\ \text { o } & 20592 \\ \text { I } & 265 \text { I } \\ 2 & 297 \\ 3 & 4 I \\ 4 & 7 \\ 5 & 0 \\ 6 & \text { I }\end{array}$

Denoting by $s_{\imath}$ the number of policies with $i$ claims in a certain period, it is shown by means of the recurrence formula of the Poisson distribution

$$
\frac{s_{\imath+1}}{s_{\imath}}=\frac{q}{i+\mathrm{I}}
$$

where $q$ is the expected number of claims in unit time, that the present data are not homegeneous. It is therefore assumed that the portfolio consists of careful drivers and accident-prone drivers and that the expected value $s_{\imath}$ can be denoted by

$$
s_{\imath}=N\left(q_{1}\right) e^{-q_{1}} \frac{\left(q_{1}\right)^{2}}{i !}+N\left(q_{2}\right) e^{-q_{2}} \frac{\left(q_{2}\right)^{i}}{i !}
$$




$$
\begin{gathered}
\text { with } N(q)=N\left(q_{1}\right)+N\left(q_{2}\right) \\
\text { and } q N(q)=q_{1} N\left(q_{1}\right)+q_{2} N\left(q_{2}\right)
\end{gathered}
$$

By means of some simple transformations and a few logical assumptions-which are however not mathematically substantiated -the parameters $N\left(q_{1}\right), N\left(q_{2}\right), q_{1}$ and $q_{2}$ are calculated for this data. The distribution emerging from these simple assumptions is specified in table I.

On the other hand in a previous paper $[\mathrm{I}]$ the same observations were fitted with a compound Poisson distribution of the form

$$
\begin{gathered}
s_{i}=\int_{0}^{\infty} \frac{e^{-q} q^{i}}{i !} d u(q) \\
\text { with } d u(q)=\frac{\tau^{a} e^{-\tau q} q^{a-1}}{\Gamma(a)} d q[a, \tau>0] .
\end{gathered}
$$

Consequently the negative binomial distribution

was derived with

$$
s_{i}=s(i)=\left(\begin{array}{c}
i+a-\mathrm{I} \\
i
\end{array}\right)\left(\frac{\tau}{\mathrm{I}+\tau}\right)^{a}\left(\frac{\mathrm{I}}{\mathrm{I}+\tau}\right)^{i}
$$

$$
\mu=\frac{\tau}{a} \text { and } \quad \delta^{2}=\frac{a}{\tau}\left(\mathrm{I}+\frac{a}{\tau}\right)
$$

The parameters $a$ and $\tau$ were evaluated as:

$$
\begin{aligned}
& a=1,0585 \\
& \tau=7,3394 .
\end{aligned}
$$

A comparison between the method of Tröblinger and a negative binomial distribution is shown in the following table I:

Table I

\begin{tabular}{c|r|r|r}
\hline \multirow{2}{*}{$\begin{array}{c}\text { Number of } \\
\text { claims } \\
\text { per policy }\end{array}$} & observed & Tröblinger & $\begin{array}{c}\text { negative } \\
\text { binomial }\end{array}$ \\
\cline { 2 - 4 } & 20592 & 20589 & 20607 \\
\hline 0 & $265 \mathrm{I}$ & 2656 & $26 \mathrm{I} 7$ \\
$\mathrm{I}$ & 297 & 289 & 320 \\
2 & $4 \mathrm{I}$ & 44 & 40 \\
3 & 7 & 7 & 5 \\
4 & $\mathrm{O}$ & $\mathrm{I}$ & 0 \\
5 & $\mathrm{I}$ & 0 & 0 \\
6 & & & \\
\hline
\end{tabular}


As may be seen, the Tröblinger approximation is much closer than the compound Poisson process. However when allowance is made for the fact that the significant part of the data consists of only 5 groups and for the extra parameters used in the Tröblinger approximation, a $x^{2}$-test shows that the result cannot be regarded as statistically different. Certainly no justification exists for the assumption by Tröblinger that the closeness of the representation is a definite proof that there are only two categories of drivers, the careful and the accident-prone.

Nevertheless is does not seem unreasonable to regard Gürtler's and Tröblinger's assumptions as a rough approximation and results based on such assumptions are not therefore without value.

In his examinations, Gürtler is considering six rebate classes from class $o$ to class 5 , each class indicating directly the number of years of accident-free driving. Whenever a driver suffers an accident, he is placed back in class o. Assuming a constant claim probability, the observed portfolio will stabilize after five years if withdrawals and new entries are disregarded. The resulting distribution is indicated in table II.

\section{ALTERATIONS IN THE MODEL}

The relegation of a driver involved in a traffic accident into class o is no longer usual in Germany or in Switzerland. It is evident that a more refined procedure will lead to a better separation between good and bad risks. Up to the latest rate revision in Switzerland, a driver who had caused an accident was relegated by two rebate classes. The latest rate revision provides for a relegation by three classes. Our calculations are, however, based on the formula previously in use.

Moreover for classification purposes the scale was extended to eight classes. Classes $0-2$ correspond to class 0 in Gürtler's model, class 7 corresponds to Gürtler's class 5. These assumptions take into account the observed trend in claim rates according to the driving experience and provide for a bonus only after two years of accident-free driving. It is obvious that stabilization of the policies into the different rebate classes will take more than five years and for the present data it will take approximately 28 years. From this the conclusion might be reached that such a model is 
useless for practical applications, but since the theoretical assumption of stabilization is hardly ever realized, this argument is of doubtful significance.

A comparison between the two models and their division of drivers into the different rebate classes is shown in table II:

\section{Table II}

\begin{tabular}{c|c|c||c|c|c}
\hline \multirow{2}{*}{$\begin{array}{c}\text { Rebate } \\
\text { class }\end{array}$} & \multicolumn{2}{|c|}{ Gürtler's model } & \multirow{2}{*}{ Altered model } \\
\cline { 2 - 3 } & $\begin{array}{c}\text { careful } \\
\text { driver }\end{array}$ & $\begin{array}{c}\text { accident- } \\
\text { prone } \\
\text { driver }\end{array}$ & $\begin{array}{c}\text { Rebate } \\
\text { class }\end{array}$ & $\begin{array}{c}\text { careful } \\
\text { driver }\end{array}$ & $\begin{array}{c}\text { accident- } \\
\text { prone } \\
\text { driver }\end{array}$ \\
\hline 0 & 855 & 632 & $0-2$ & 47 & $93 \mathrm{I}$ \\
$\mathbf{I}$ & 774 & 232 & 3 & 105 & $4 \mathrm{I}$ \\
2 & 702 & 85 & 4 & 166 & 17 \\
3 & 639 & 32 & 5 & 827 & 7 \\
4 & 576 & 12 & 6 & 747 & 3 \\
5 & 5454 & 7 & 7 & 7108 & 1 \\
\hline & 9000 & 1000 & & 9000 & 1000 \\
\hline
\end{tabular}

It is obvious that the breakdown between careful and accidentprone drivers is far better in the altered model and that the classification procedure is more appropriate to the underlying risk than in Gürtler's model. Hence it may be assumed that the error ratios for this model will be smaller than in Gürtler's model.

\section{DIFFERENT BONUS SYSTEMS}

For his models, Gürtler has tested different bonus systems and derived a minimum $E R$ of 0,545 .

A minimum $E R$ of 0,545 is certainly quite alarming since it means that in the best case still more than half of the premiums are not levied according to the underlying risk. The purpose of this paper is to show that the $E R$ depends directly on the basic assumptions and may be improved by starting from an altered model.

\section{a. The Bonus with Linear Increments}

The German tariff usually provides for a bonus system increasing 
in equidistant steps of $10 \%$ of the premium up to a maximum credit of $50 \%$. In the following we shall describe the detailed calculation of the $E R$ for one case and only the results for the other systems.

As mentioned before it is assumed that a portfolio consists of 9000 careful drivers with an annual claim rate of $0, \mathrm{I}$ and I 000 accident-prone drivers with a claim rate of $\mathrm{I}, \mathrm{O}$. Thus the careful drivers will cause in a year 900 claims, the prone drivers I 000 claims. The average claim cost is I 200 , i.e. the total loss 2280000 which leads to a net flat rate of 228 for each driver. On the other hand the individual tariff rate would be I20 for a careful and I 200 for an accident-prone driver.

This net flat rate of 228 is valid only if no bonus is granted. For a bonus system an additional loading becomes necessary because otherwise the charged premiums would be too small to cover the cost of claim.

In Gürtler's model the distribution of drivers and the allocated credit for careful driving is as follows:

\section{Table III}

\begin{tabular}{|c|c|c|c|c|c|}
\hline \multirow{2}{*}{$\begin{array}{c}\text { Rebate } \\
\text { class }\end{array}$} & \multicolumn{3}{|c|}{ Drivers } & \multirow{2}{*}{$\begin{array}{l}\text { Credit } \\
\text { in } \%\end{array}$} & \multirow{2}{*}{$\begin{array}{l}\text { Total } \\
\text { credit } \\
\text { in } \%\end{array}$} \\
\hline & careful & prone & total & & \\
\hline 0 & 855 & 632 & 1487 & o & o \\
\hline I & 774 & 232 & 1006 & Io & 1,006 \\
\hline 2 & 702 & $8_{5}$ & $7^{87}$ & 20 & $\mathrm{I}, 574$ \\
\hline 3 & 639 & 32 & 671 & 30 & 2,013 \\
\hline 4 & $57^{6}$ & I 2 & $5^{88}$ & $4^{\circ}$ & $2,35^{2}$ \\
\hline \multirow[t]{2}{*}{5} & 5454 & 7 & $546 \mathrm{I}$ & 50 & 27,305 \\
\hline & 9000 & IOOO & 10000 & & 34,25 \\
\hline
\end{tabular}

Thus the total sum of credits granted to all drivers with an accident-free driving record during a calendar year is $34,25 \%$ of the office premium. In other words, the net flat rate of 228 necessary to meet the claim expenses represents $65,75 \%$ of the office premium. The full office premium therefore is determined at 346,77 .

The charged premiums and the absolute amounts of error are shown in the next table: 
Table IV

\begin{tabular}{|c|c|c|c|c|c|}
\hline \multirow[b]{2}{*}{$\begin{array}{c}\text { Rebate } \\
\text { class }\end{array}$} & \multirow[b]{2}{*}{$\begin{array}{c}\text { Office } \\
\text { premium }\end{array}$} & \multirow[b]{2}{*}{ Bonus } & \multirow[b]{2}{*}{$\begin{array}{l}\text { Charged } \\
\text { premium }\end{array}$} & \multicolumn{2}{|c|}{ Absolute error } \\
\hline & & & & $\begin{array}{l}\text { careful } \\
\text { driver }\end{array}$ & $\begin{array}{l}\text { accident- } \\
\text { prone } \\
\text { driver }\end{array}$ \\
\hline 0 & 346,77 & 0 & 346,77 & 226,77 & 853,23 \\
\hline I & 346,77 & $10 \%$ & $3^{12,09}$ & 192,09 & $887,9 \mathrm{I}$ \\
\hline 2 & 346,77 & $20 \%$ & 277,42 & I $57,4^{2}$ & 922,58 \\
\hline 3 & 346,77 & $30 \%$ & 242,74 & 122,74 & 957,26 \\
\hline 4 & 346,77 & $40 \%$ & 208,06 & 88,06 & 991,94 \\
\hline 5 & 346,77 & $50 \%$ & I 73,39 & 53,39 & $1026,6 \mathrm{I}$ \\
\hline
\end{tabular}

Finally the $E R$ is computed according to the following schedule:

Table $V$

\begin{tabular}{|c|c|c|c|c|c|c|c|}
\hline \multirow[b]{2}{*}{$\begin{array}{c}\text { Rebate } \\
\text { class }\end{array}$} & \multicolumn{3}{|c|}{ Careful driver } & \multicolumn{3}{|c|}{ Prone driver } & \multirow[b]{2}{*}{$\begin{array}{c}\text { Sum of } \\
\text { errors }\end{array}$} \\
\hline & number & $\begin{array}{l}\text { error } \\
\text { per } \\
\text { driver }\end{array}$ & $\begin{array}{l}\text { total } \\
\text { error }\end{array}$ & $\begin{array}{c}\text { num- } \\
\text { ber }\end{array}$ & $\begin{array}{l}\text { error } \\
\text { per } \\
\text { driver }\end{array}$ & $\begin{array}{l}\text { total } \\
\text { error }\end{array}$ & \\
\hline o & 855 & 226,77 & I93 888,35 & 632 & 853,23 & $53924 I, 36$ & \\
\hline I & 774 & I92,09 & I 48677,67 & 232 & $887,9 \mathrm{r}$ & 205995,12 & \\
\hline 2 & 702 & I 57,42 & I IO 508,84 & 85 & $922,5^{8}$ & 78419,30 & \\
\hline 3 & 639 & $\mathrm{I} 22,74$ & $7^{8} 43^{\circ}, 86$ & 32 & 957,26 & 30632,32 & \\
\hline 4 & 576 & 88,06 & $5^{\circ} 722,56$ & I 2 & $99 \mathrm{I}, 94$ & II 903,28 & \\
\hline \multirow[t]{2}{*}{5} & 5454 & 53,39 & 291 I 89,06 & 7 & $\mathrm{IO} 26,6 \mathrm{I}$ & $7 \mathrm{r} 86,27$ & \\
\hline & & & 8734 I 7,34 & & & 873377,65 & I 746794,98 \\
\hline
\end{tabular}

This result is rather discouraging, since it implies that only a small improvement has been made by applying a bonus system. As shown before the $E R$ without any bonus is 0,853 and the improvement only 0,087 or $10,2 \%$.

If the same computations are made for the altered model, an $E R$ of $0,7 \mathrm{I}_{4}$ is obtained which also is not very satisfactory.

It is obvious that an improvement may be obtained if the rebate scale is enlarged. In fact it is clear that under these assumptions 
a careful driver should pay only ro $\%$ of the office premium since the loss ratio of the prone driver is ten times as high. For some linear rebate systems the results as follows were obtained:

Table VI

\begin{tabular}{c|c|c|c}
\hline \multirow{2}{*}{$\begin{array}{c}\text { Rebate } \\
\text { class }\end{array}$} & System I & System II & System III \\
\cline { 2 - 4 } & \multicolumn{2}{|c|}{ bonus in \% of office premium } \\
\hline $0-2$ & 0 & 0 & 0 \\
3 & Io & I5 & I8 \\
4 & 20 & 30 & 36 \\
5 & 30 & 45 & 54 \\
6 & 40 & 60 & 72 \\
7 & 50 & 605,40 & 90 \\
\hline office & $390, \mathrm{I}_{4}$ & $0,53 \mathrm{I}$ & 0,459 \\
\hline premium & $0,7 \mathrm{I} 4$ & & \\
\hline
\end{tabular}

Systems II and III are already better than the so-called "optimum $E R$ " by Gürtler.

\section{b. A Combined Bonus System}

The combined bonus system consists of two parts:

- a fixed bonus,

- a bonus with linear increments.

Such an agreement seems logical because in the previous system III the office premium amounted roughly to 905 . The prone driver still did not pay his individual premium, but also the careful driver in rebate class 7 did not pay enough. In fact, after deduction of the bonus this driver was only charged with 90.50 instead of 120 . Since the drivers at both ends of the rebate system were charged with too small a premium, the other rebate classes consequently paid too much.

Rebate system IV was therefore constructed as follows: 


\begin{tabular}{c|c|c|c|c|c}
\hline \multicolumn{6}{c}{ Rebate class } \\
\hline $0-2$ & 3 & 4 & 5 & 6 & 7 \\
\hline \multicolumn{6}{|c|}{ bonus in \% of office premium } \\
\hline 0 & 50 & 60 & 70 & 80 & 90 \\
\hline
\end{tabular}

Under these assumptions the office premium amounted to I020 and the $E R$ to 0,305 .

Sachs [6] has already stressed that a bonus system will not work properly if the office premium is smaller than the premium needed for the poorest risk. We can therefore tackle our problem from another angle by determining the bonus scale of the form, $a, a+t$, $a+2 t, \ldots$ for the case where the following two suppositions are fulfilled:

I. The office premium is $\mathbf{2} 200$.

2. The bonus for drivers in rebate class 7 is $90 \%$ of the office premium.

By two simple equations the parameters $a$ and $t$ are determined as:

$$
\begin{aligned}
& a=87,77 \% \\
& t=0,5575 \%
\end{aligned}
$$

which means that the bonus is almost constant. For such a bonus system, the remaining $E R$ is only 0,064 .

\section{c. The Constant Bonus}

The "optimum bonus system" in Gürtler's examinations was a constant bonus. This result seems logical and is not surprising because it already lies in the assumption of careful and accidentprone drivers. It is evident that a constant bonus has to emerge as the best solution for only two claim rates, while this system fails when more claim rates are involved.

If a constant bonus is determined in such a way that the drivers in rebate class $0-2$ pay a premium of 1200 and all other drivers the remaining needed premium of 122.63 , an $E R$ of 0,065 is gained. The smallest $E R$ is found when drivers in rebate class $0-2$ pay a premium of $I 200$ and drivers in the rebate classes $4-7$ contribute 
an annual premium of 120 . The remaining needed premium is divided in equal shares among the drivers in rebate class 3 . The charged premium for these drivers amounts to 282.74 . In such a case the $E R$ is 0,059 or almost ten times better than Gürtler's optimum. If an error of only $6 \%$ could really be realized in practice, it would be most satisfactory. The concept of absolute fairness of the tariff is never fulfilled and not an absolute standard. There are certain limits to the accuracy of any rating procedure and to ask for a rating procedure with an $E R=0$ is unrealistic.

\section{CONCLUSIONS}

These investigations are based on some simple assumptions and the results cannot be considered as a mathematical proof of whether or not a bonus system leads to a fair premium. All what has been done is to take Gürtler's basic model, to change a few features of this model and to show that the so-called error ratio can still be considerably improved. The alterations of the model seem logical. Neither in Switzerland nor in Germany is a driver who has been involved in a traffic accident relegated from the highest to the lowest rebate class. This has been the case in Switzerland since before 1958. Our investigations show that some improvement has been realized when the relegation procedure is refined.

To provide for a longer waiting period seems reasonable too, especially when the trend of the claim rates according to the driving experience is taken into account.

The $E R$ for the different bonus systems according to Gürtler and the altered model are shown in the next table:

Table VII

\begin{tabular}{|c|c|c|}
\hline Bonus system & Gürtler's model & Altered model \\
\hline no bonus & 0,853 & 0,853 \\
\hline linear bonus I & 0,766 & 0,714 \\
\hline " $\quad$ II & & $0,53 \mathrm{I}$ \\
\hline , III & & 0,459 \\
\hline,$\quad$ IV & & 0,305 \\
\hline$, \quad, \quad, \quad \mathrm{V}$ & & 0,064 \\
\hline constant bonus & 0,545 & 0,065 \\
\hline optimum bonus & 0,545 & 0,059 \\
\hline
\end{tabular}


The results for the altered model show marked improvement and lead to the following conclusions

I) A more refined relegation system leads to a better breakdown between careful and prone drivers

2) The number of rebate classes should not be too small to give a reasonable possibility that a good driver involved at random in a traffic accident can obtain a substantial bonus again after a few years.

3) A bonus should not be granted too quickly.

4) The office premium should be rather high, so that a substantial bonus-at least $50 \%$-could be granted after a few years with an accident-free driving record

\section{REFERENCFS}

[I] Derron Marcei Mathematische Probleme der Automobilversicherung, Mitteilungen der Vereinigung schweizerischer Versıcherungsmathematıker, 1962

[2] Gurtler, Max Das subjektıve Risiko in der Motorfahrzeugversicherung, Ze1tschrift fur die gesamte Versicherungs-Wissenschaft, I960

[3] Gurtler, Max Der Bonus als Mittel zur Erfassung des subjektiven Risikos, Zeitschrift fur die gesamte Versicherungs-Wissenschaft, I96I

[4] Gurtler, Max Der optimale Bonus, Zeitschrift fur die gesamte Versicherungs Wissenschaft 1962

[5] Mehring, Johannes Premium Rates in the German Motor Insurance Business, The ASTIN Bulletin, vol III, part I, I963

[6] Sachs, Wolfgang Der Nutzen des Bonus in der Kraftfahrversicherung, Versicherungswirtschaft, I4/I96I

[7] Troblinger, Alfred Mathematische Untersuchungen zur Beitragsruckgewahr in der Kraftfahrversicherung, Blatter der deutschen Gesellschaft fur Versicherungsmathematik, I96I 